\title{
Apprenticeship: precision optics manufacturing technician
}

\section{Mike Mandina, Jim VanKouwenberg}

Mike Mandina, Jim VanKouwenberg, "Apprenticeship: precision optics manufacturing technician," Proc. SPIE 11143, Fifteenth Conference on Education and Training in Optics and Photonics: ETOP 2019, 1114320 (2 July 2019); doi: 10.1117/12.2523781

SPIE Event: Fifteenth Conference on Education and Training in Optics and Photonics: ETOP 2019, 2019, Quebec City, Quebec, Canada 


\title{
Apprenticeship: precision optics manufacturing technician
}

\author{
Mike Mandina, JimVanKouwenberg* \\ Optimax Systems, 6367 Dean Parkway, Ontario, NY 14580 \\ *jvank@optimaxsi.com
}

\begin{abstract}
As U.S. manufacturing works to overcome a technical skills gap, apprenticeship is gaining favor as a post-secondary educational path. Registered apprenticeship is a structured program that requires on the job training of an employee, accompanied by related instruction, and a progressive wage scale as the apprentice progresses through the program. This presentation describes how the Occupation Title for a Precision Optics Manufacturing Technician was defined for the industry, and approved by the US Department of Labor (USDOL). The occupation was later deemed apprenticeable by the DOL, and the apprenticeship was designed and registered with NY State. The program entails a three year (6,000 hour) rotation through every department of an optics manufacturing firm, with defined outcomes regarding hours of experience and competencies gained. In this program, structured, hands on technical training is combined with theoretical class room learning to develop highly skilled manufacturing technicians. This presentation will explain many of the details surrounding registered apprenticeship, including adjustments and results encountered during the first three years of the Optimax program.
\end{abstract}

Keywords: Apprenticeship, workforce training, OJT, related instruction

\section{Introduction}

\subsection{Exploring apprenticeship}

Following a 2015 visit to the Obama White House, Optimax was encouraged to consider a registered apprenticeship program. The Obama administration was investing heavily in apprenticeship through the American Apprenticeship Initiative, and was interested in the creation of new programs, especially in industries that were not well represented in traditional apprenticeships. An Optimax team was created to work through the process, and nearly two years later Optimax registered the trade with New York State.

\section{Creating the program}

\subsection{Identifying the gap}

Optimax has long had a training program for optics manufacturing technicians. There is a broad range of skill sets required by our lean manufacturing process. Manufacturing is done in specialized cells that are capable of taking material from a raw blank to a polished optic with interferometrically measured optical surfaces. Each cell is designed to accommodate a defined range of product based on size, shape, material, and/or quantity. Methods and technology vary significantly from cell to cell. Existing training has proven effective at bringing technicians up to speed in one or more cells, but very few newer technicians are well versed across all manufacturing areas. There are many highly skilled opticians, but few that would be considered "Master Opticians", a title that might be considered dated. The intention became to create a group of technicians that would have broader understanding of all manufacturing methods in use or being developed at Optimax. Upon completion of the three year program, journeyworkers will have a variety of opportunities available to them. Ideally, these journeyworkers will continue to serve the manufacturing area in some capacity. 


\subsection{Developing the Occupation Title}

Registering an apprenticeship requires a federally recognized occupation title for the trade. There were no titles in the federal databases that closely described the work in this industry, so a trade description was created. Based on industry acceptance, an outline was created to follow "The National Precision Optics Skill Standards for Technicians, $2{ }^{\text {nd }}$ Edition"1, published by Op-Tec in 2013. This set of standards describes many aspects of the trade well, and received endorsement by several industry organizations, including APOMA, Colorado Photonics Industry Association, Florida Photonics Cluster, New Mexico Optics Industry Association, and the Rochester Regional Photonics Cluster. Using these standards, work was done with the USDOL to define the Occupation Title. The work process outline drafted was added to the Dictionary of Occupational Titles (D.O.T.) as CODE 716.382-018². It can also be found as an ONET listing, $89917 \mathrm{~A}^{3}$. These two databases contain the complete listing of federally recognized occupations. While each of these descriptions should be improved, the USDOL recognized the occupation as apprenticeable on March 1, 2016.

\subsection{Creating the New York State apprenticeship outline}

Registered apprenticeships in the United States are monitored by either the USDOL or a state apprenticeship council. Twenty five states have their own apprenticeship councils, and the other twenty five rely on federal monitoring. Apprenticeship programs registered in all 50 states are recognized at the federal level. The primary difference between the two models is having state resources available to help develop and monitor a program, as opposed to federally monitored states, which may have only one representative responsible for one or more states. New York has a state run Apprenticeship and Training Council. Working with New York State, a trade outline was created that covered the work processes defined in the occupation title. The trade outline consists of Appendices A and B. Appendix A describes the work processes required for the on the job training (OJT) portion of the program, and Appendix B describes the related instruction (RI). In Appendix A, work processes are laid out in broad terms to allow some latitude in how things are trained from one company to another. An approximate number of hours for each work process is defined. There are a number of shorter processes, Workplace Orientation, Materials Selection, Planning and Verifying Fabrication Processes, for examples, that are each assigned anywhere from 100 to 300 hours. The bulk of the NYS program hours are assigned to the work processes of Shaping and Finishing (3250 hours), and Measuring, Inspecting, and Packaging (1750 hours). Sub-headings under Shaping and Finishing include; use of appropriate power tools, handling of optical materials, measure and record dimensionality, operate all manner of machinery, maintain a clean work area, and follow prescribed equipment maintenance procedures. Included under Measuring, Inspection, and Packaging are; adhere to inspection plans, use appropriate metrology tools, document final inspection results, package optics for shipping, adhere to instrument calibration system. A copy of the NYS outline is available on line ${ }^{4}$.

New York State favors time based programs, requiring a certain number of hours applied to each work process in the trade outline. Other options are competency based programs, or hybrids of time and competency. A competency based program requires defined competencies for each of the work processes, and independent testing to determine the required skills have been mastered. A hybrid program also includes a prescribed minimum time on task requirement before competency can be tested. This apprenticeship is registered as a time based program with the state, but competency expectations are defined internally for each of the rotations. For every year (2,000 hours) of OJT, 144 hours of RI is required. Appendix B outlines the classroom topics that apply to the program. Related instruction is also approved and monitored by USDOL or the state agency. RI can be delivered in many formats, from community college or technical schools, to on-line or in-house programs. In New York, the apprenticeship council approves and monitors the RI coursework. In other states, the RI would be controlled by the state or federal councils, depending on the apprenticeship structure in the state.

\subsection{Defining the apprenticeship program at Optimax}

The OJT portion of the training consists of a three year rotation through 23 departments at Optimax. Apprentices begin with six weeks in purchasing/production control, followed by six weeks in blank prep. This provides a foundational understanding of many material properties and material control procedures that are required. The next rotation is nine weeks in a spherical manufacturing department, followed by eight weeks in quality control. The majority of the following time (95 weeks) is spent in manufacturing areas, including plano, spherical, cylindrical, aspheric, and free form. The balance (35 weeks) is divided among the sales, quality, coating, assembly, tool crib, machine shop, and maintenance 
departments. The time spent in each of these areas is applied to the subheadings in Appendix A of the trade outline. Appendix A does not define the geometry of the optics the apprentices manufacture as requirements. Therefore, if a company manufactures primarily spherical or plano optics for example, the time the apprentice spends making those optics will be increased, and the hours will be applied to the appropriate work processes. The order of the Optimax rotation is designed to provide the apprentices experience in the skill sets required for subsequent operations. For example, when they arrive in the assembly department, they have already spent eight weeks in final QC, so cleaning and handling finished optics has been mastered. Therefore, the training in assembly can focus on assembly methods. Training is done by subject matter experts in each area. The ratio of apprentice to journey worker is 1:1, as required by NYS.

Related Instruction is provided using online courses for topics such as OSHA 10 and Sexual Harassment Prevention. Most of the Trade Theory, Science, and Math requirements are taught at the community college. Monroe Community College (MCC) offers optics courses, as well as math, blueprint reading, and metrology courses. Apprentices enroll in classes at the college, and in credit and non-credit courses that MCC delivers at Optimax. All coursework is paid for by the employer, and significant grant funding is available to cover the costs of related instruction. All of the RI delivered by MCC can be applied to a certificate or two year degree at the college should the apprentice decide to pursue that path. Work is being done to provide online credit bearing community college courses that will meet the RI requirements. Other options for RI include local community and technical colleges, ToolingU (an online training platform), and BOCES or technical high schools for courses in math, blue print reading, technical writing, etc.

\section{Outcomes and observations}

\subsection{Adding apprentices to the program}

Recruitment is done from the incumbent work force. Open enrollment periods are posted as necessary. Candidates are able to apply on line to become part of the program. Regulations require that candidates are rank ordered by a selection criteria that the employer defines. Our process includes Work Keys math and reading comprehension testing administered by the local Workforce Investment Board, a team interview process, and an essay. These results are captured in a rubric that provides the rank ordering of the candidates. The math testing is deemed necessary because of the math rigor required for much of the RI. Candidates with poor math skills will likely fail at the required optics coursework. The math and reading tests, as well as the interview and essay process are not defined by the state. The employer has flexibility regarding their ranking process, but once it's defined, the state will enforce it.

\subsection{Administration}

NYS requires apprentices to record the hours spent on each work process in a blue book. In traditional apprenticeships, this is a physical book. A digital book was created for this program. The apprentices meet with a NYS representative every six months to go over the blue book and verify their wage progression. To ensure the effectiveness of the program, a steering committee was convened. The steering committee meets monthly to review the progress of the apprentices, and evaluate any changes to the rotation. The committee is also responsible for performance evaluations and wage increase decisions based on feedback from the OJT trainers. A database was created for tracking the apprentices through the program. The database provides automatic email notification to HR and to the manufacturing area that an apprentice will be entering. The apprentices meet as a group monthly to discuss the program. This is an opportunity to suggest improvements to the process, remind them of their responsibilities in the program, and make sure they are on track to complete the requirements. Administration of the program averages about ten hours per week. There are programs available in NYS to provide some of these administrative services through an intermediary sponsor. This is a new approach that is gaining favor in several states.

\subsection{Observations}

As the program was being developed, there was some hesitancy on the part of the team leaders and group leaders. The concerns centered on teams losing some of their better performers for three years, not knowing where the apprentices 
would end up after the program, and having to deal with unknown performers rotating in and out of their areas for two to three months at a time. These concerns have been eliminated to the point that some group leaders have asked for the apprentices to spend more time in their areas. As the apprentices' skills have developed, they have become sought after resources to help in bottleneck situations throughout the company.

The program has also gained acceptance with potential candidates. The first open enrollment period yielded enough candidates for a year. The second year required multiple open enrollment periods to fill the openings every three months. The most recent open enrollment provided four candidates including two women. We now have a number of candidates anxiously waiting the next open enrollment period.

At the time of this writing, there are ten active apprentices in the program. The first completion will be in June of this year. At this point, two apprentices have started the program that eventually dropped out. One left the company, and one found that the continual change of work responsibilities and reporting structure did not suit their personality. That employee is still with the company and performing well in their previous role.

A number of other companies in the area have registered or are considering registering apprentices into this trade title. Work is being done to increase the number of apprentices in this trade across the United States. Optimax looks forward to helping other companies through the process by sharing results and best practices

\section{Next steps}

\subsection{Additional programs}

In July 2019, we expect to register two new apprenticeships with NYS. The IMT (Industrial Manufacturing Technician) is an eighteen month, entry level program intended to bring people with no skills up to the point that they can effectively contribute as a team member, and they may gain enough skill to register in the precision optics manufacturing (POM) program. A portion of the work they will do during the IMT may be applied to the POM apprenticeship. The second trade will be electro-mechanical technician. This program is designed to prepare candidates for a role in the facilities and machine maintenance department. As maintenance staff ages out of the work force, filling these positions becomes increasingly important across all industries. We look forward to success in these programs similar to our success with the POM program.

\section{Conclusions}

\subsection{Regarding the future of apprenticeships}

We feel strongly that it is important for apprenticeship to gain acceptance as a valuable post-secondary education. While our work is focused on a very specific manufacturing industry, apprenticeships are being registered in the fields of health care, mechatronics, education, skilled trades, and more. Five years after completion, the average salary of an apprenticeship completer is higher than the median earnings of a person that completed a bachelor's degree. Add to that, the average outstanding loan debt for a bachelor's degree holder was $\$ 24,100$ in $2013^{5}$. It is up to us to create an environment similar to the apprenticeship models in Germany and Switzerland, where completion of an apprenticeship is as highly regarded as completion of a university degree, and fifty percent or more of students choose the path of apprenticeship. We also have to recognize that apprenticeship is not the end of the post-secondary education, but a foundation that may well lead to additional higher learning. 


\section{References}

[1] OP-TEC/UCF, [The National Precision Optics Skill Standards for Technicians, 2nd Edition] $<$ http://www.op-tec.org/precision-optics-skill-standards-2nd-edition>

[2] "Dictionary of Occupational Titles (D.O.T.) CODE 716.382-018," < https://occupationalinfo.org/71/716382018.html> [3] "ONET code: 89917A, title: Precision Lens Grinders and Polishers," $<$ https://occupationalinfo.org/onet/89917a.html> [4] New York State Department of Labor "Precision Optics Manufacturing Technician" https://www.labor.ny.gov/apprenticeship/pdfs/activetrades/45-560.pdf

[5]U.S. Department of Education, National Center for Education Statistics, "Four Years After a Bachelor's Degree: Employment, Enrollment, and Debt among College Graduates", May 2017, Table 12, page 77. 